\title{
Engineering Fusarium Head Blight Resistance in Wheat by Expression of a Fusion Protein Containing a Fusarium-Specific Antibody and an Antifungal Peptide
}

\author{
He-Ping Li, ${ }^{1,2}$ Jing-Bo Zhang, ${ }^{1,3}$ Run-Ping Shi, ${ }^{1}$ Tao Huang, ${ }^{1}$ Rainer Fischer, ${ }^{4}$ and Yu-Cai Liao ${ }^{1,3}$ \\ ${ }^{1}$ Molecular Biotechnology Laboratory of Triticeae Crops, ${ }^{2}$ College of Life Science, and Technology, and ${ }^{3}$ College of Plant \\ Science and Technology, Huazhong Agricultural University, Wuhan 430070, PR China; ${ }^{4}$ Institute of Molecular Biotechnology, \\ RWTH Aachen, Germany
}

Submitted 1 April 2008. Accepted 17 May 2008.

Fusarium head blight (FHB) or scab of wheat is a devastating disease in warm and humid regions at wheat-flowering periods worldwide. Natural resistance against FHB pathogens is inadequate and the development of FHBresistant wheat cultivars has been a challenge. Expression of pathogen-specific antibodies in plants has been proposed as a strategy for crop protection. In this study, an antibody fusion protein comprising a Fusarium-specific recombinant antibody derived from chicken and an antifungal peptide from Aspergillus giganteus was expressed in wheat as a method for protecting plants against FHB pathogens. Plants expressing the antibody fusion displayed a very significantly enhanced resistance in $\mathrm{T} 2$ and $\mathrm{T} 3$ generations upon single-floret inoculation with the macroconidia of Fusarium asiaticum, the predominant species causing FHB in China, indicating a type II resistance. Spraying inoculation further revealed an enhanced type $I$ resistance in the transgenic wheat plants. Remarkably, more grains were produced in the transgenic plants than the nontransgenic controls. Our results demonstrated that the antibody fusion protein may be used as an effective tool for the protection of crops against FHB pathogens.

Additional keyword: F. asiaticum.

Fusarium head blight (FHB) or scab of wheat and other small cereal grains caused by Fusarium graminearum Schwabe sensu lato (teleomorph: Gibberella zeae (Schwein.) Petch) is an economically devastating disease worldwide (Bai and Shaner 2004). FHB takes place both in the field and during storage, causing huge losses of crop yields and producing mycotoxins that are directly accumulated in grains and, consequently, enter food chains. In recent times, FHB has reached epidemic proportions in North America and Europe (Windels 2000). In China, epidemics of FHB occur frequently in the middle and downstream regions of the Yangtze River and in the Heilongjiang province in the northeastern region (Chen et al. 2000). F. asiaticum and F. graminearum are two phylogenetic species responsible for FHB of wheat, with the former being the predominant species (Gale et al. 2002; Qu et al. 2008). Fusarium mycotoxins are among the main fungal my-

Corresponding author: Yu-Cai Liao, Telephone/Fax: +86-27-87283008; E-mail: yucailiao@mail.hzau.edu.cn; ycliao06@yahoo.com.cn

H.-P. Li and J.-B. Zhang contributed equally to this work. cotoxin contaminations in food and livestock (Bai 1997), and some human diseases, such as Kashi-Neck diseases and esophageal cancer, have been epidemiologically associated with consumption of trichothecence mycotoxins (Chen et al. 2000).

The most effective control strategy for fungal diseases is the prevention of infection in the field and during storage by endogenous expression of resistance genes. However, no germplasm exists that provides effective innate resistance to this pathogen under high disease pressure (Liu and Anderson 2003; Windels 2000) and the development of resistant wheat cultivars with suitable agronomic traits has been a challenge with conventional strategies (Dahleen et al. 2001; Liu 2002). Therefore, alternative approaches are required to protect plants against FHB pathogens and to reduce mycotoxin production (Anand et al. 2003; Chen et al. 1999; Di and Turner 2005; Mackintosh et al. 2007; Makandar et al. 2006; Okubara et al. 2002).

Antibodies are defense molecules produced by all vertebrates which can recognize and bind pathogen-specific antigens and, thus, help to eliminate pathogens from the body. Fungus-specific antibodies have been shown to reduce fungal growth in vitro (Hiatt et al. 2001). Full-size antibodies and single-chain antibodies $(\mathrm{scFv})$ have been expressed in plants. Plant-derived antibodies have been developed for the protection of plants against pathogens (Boonrod et al. 2004; Peschen et al. 2004; Tavladoraki et al. 1993; Zimmermann et al. 1998) and immunomodulation (Jobling et al. 2003) in addition to their therapeutic applications. Cytoplasmic expression of a single-chain antibody against Artichoke mottled crinkle virus in transgenic tobacco has been shown to reduce viral infection and delay the progression of disease symptoms (Tavladoraki et al. 1993). Also, secretion into the apoplast of a full-size antibody recognizing intact Tobacco mosaic virus particles was shown to reduce the number of local necrotic lesions in transgenic tobacco (Voss et al. 1995). Recently, the expression of a Fusarium spp.-specific single-chain antibody in planta has been shown to confer Fusarium resistance in transgenic Arabidopsis plants comparable with that expressing an antifungal protein (Peschen et al. 2004). More importantly, expression of a single-chain antibody fused to an antifungal peptide provided a highly significant resistance against Fusarium pathogens. However, Fusarium spp.-specific antibody-mediated resistance in wheat plants has not been reported.

In this study, we used a fusion protein comprising a Fusarium spp.-specific antibody derived from chicken and an antifungal peptide from Aspergillus giganteus to transform wheat. Expression in planta of the antibody fusion was confirmed by 
reverse-transcriptase polymerase chain reaction (RT-PCR) and Western blot analysis. Single-floret injection and spraying inoculation were deployed to assess type I and type II resistance of the transgenic wheat plants. Both types of FHB resistance were significantly improved for the transgenic wheat expressing the antibody fusion. Our results demonstrate that the antibody fusion protein expressed in wheat plants can effectively control FHB disease, providing new opportunities for the development of environmentally friendly fungal pathogen control strategies.

\section{RESULTS}

\section{Transformation and characterization} of transgenic wheat plants.

The spring wheat cv. Bobwhite was used for bombardment with the plasmid containing an $A G-s c F v$ fusion gene (Fig. 1). Positive transgenic T0 plants were selected by using phosphinothricin (PPT) and PCR with the fusion-gene-specific primers. Four plants (lines 2, 4, 6, and 12) were selected to produce T1 progeny. Through T1 to T3 generations, PPT was used for the identification of transgenic plants together with PCR and RT-PCR using the fusion-gene primers AGP1 and scFvP2, which showed the presence and expression of the $A G-s c F v$ fusion gene in those plants (Fig. 2A and B). Western blot analyses confirmed that all the plants contained a protein with the expected molecular size of $32 \mathrm{kDa}$ (Fig. 2C). The genomic DNA of T3 transgenic wheat lines 2, 4, 6, and 12 were extracted and digested by the enzyme of $\mathrm{SacI}$ that cuts only once in the plant transformation vector pAHC25, followed by the hybridization with a radiolabeled probe of the antibody gene sequence. Each transgenic line has more than one distinct hybridization bands compared with the nontransgenic Bobwhite, indicating that each of the transgenic line is derived from the independently transformed plants (Fig. 3). Two to six copies of the foreign genes existed in the transgenic wheat genomes. All the transgenic plants are morphologically normal and set viable seed.

\section{FHB resistance in $\mathrm{T} 2$ transgenic wheat.}

Thirty plants from each of the four $\mathrm{T} 2$ transgenic wheat lines 2, 4, 6, and 12 were grown in a plastic house and their responses to $\mathrm{FHB}$ pathogen were evaluated by single-floret inoculation with $F$. asiaticum conidia. Nontransgenic FHBsusceptible wheat cv. Bobwhite and FHB-resistant cv. Sumai3 were inoculated and served as controls. The FHB resistance assays revealed an effective restriction of the fungus spreading on the inoculated wheat spikes of the T2 transgenic wheat plants expressing the antibody fusion. The percentages of infected spikelets in the four transgenic lines ranged from 6.7 to $7.1,8$ to 17.14 , and 13.3 to $22.2 \%$ at 7,14 , and 21 days postinoculation (dpi), respectively, whereas the nontransgenic Bobwhite had 19.6, 34.2, and 92.5\% of infected spikelets at the three corresponding times postinoculation (Table 1). Statistic analyses showed that the transgenic plants displayed significant disease reductions $(P<0.01)$ of up to 66,77 , and $86 \%$ at 7,14 , and $21 \mathrm{dpi}$, respectively, compared with that of the nontransgenic Bobwhite, which was comparable with that observed for the FHB-resistant cv. Sumai3. These results indicated that the antibody fusion protein conferred the resistance of wheat plants to Fusarium spp. spreading (i.e., a type II resistance).

\section{FHB resistance in $\mathrm{T} 3$ transgenic wheat.}

To reveal whether the type II resistance mediated by the antibody fusion is stable in different generations, 30 seeds from the T3 transgenic wheat plants of the same lines were planted in the plastic house and inoculated with single-floret injection. A high level of the enhanced FHB resistance was seen in the T3 transgenic plants expressing the antibody fusion. At 7 dpi, the infected spikelets in transgenic lines 2 and 6 ranged from 4.9 to $10 \%$, a significant disease reduction of up to $74 \%$ compared with the nontransgenic Bobwhite $(18.8 \%)$ (Table 1). At 14 and $21 \mathrm{dpi}$, all four transgenic lines had infected spikelets ranging from 13 to 32.2 and 19 to $37.9 \%$, respectively, with reductions of up to 78 and $79 \%$ compared with the nontransgenic Bobwhite (90.9\%) (Table 1). Among the transgenic lines assayed, line 2 showed the highest level of resistance at 14 and $21 \mathrm{dpi}$. Therefore, the type II resistance conferred by the antibody fusion protein is inheritable in different generations of the transgenic wheat plants.

To ascertain whether the antibody fusion mediates a type I resistance to Fusarium spp. infection, 30 plants from each of the four T3 transgenic wheat lines and the nontransgenic Bobwhite and Sumai3 assayed above for the type II resistance were inocu-

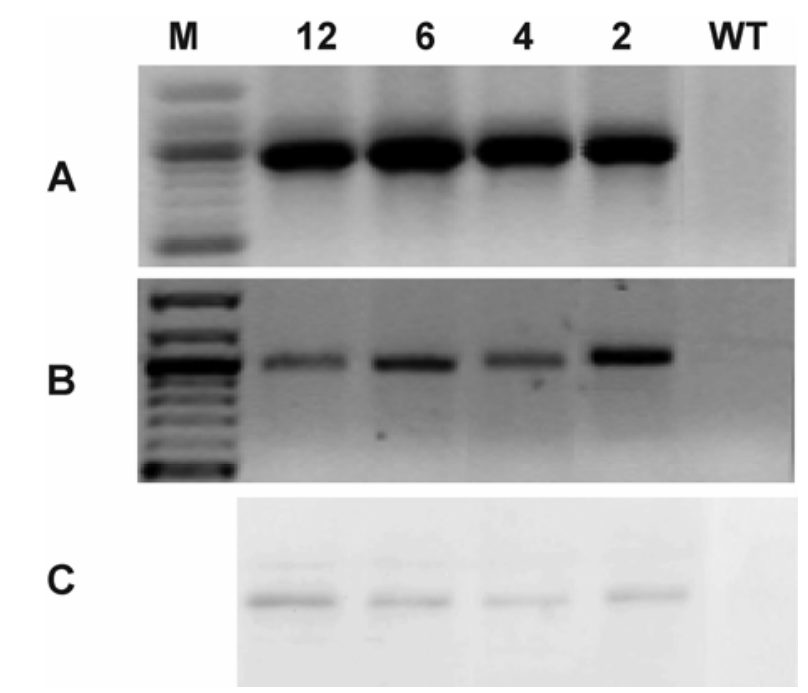

Fig. 2. Integration and expression of $A G-s c F v$ fusion gene in transgenic wheat. A, DNA isolated from leaves of T3 transgenic wheat lines 2, 4, 6, and 12 and the nontransgenic wheat cv. Bobwhite (Bob) was used in a polymerase chain reaction (PCR) assay to detect the presence of the $A G$ $s c F v$ fusion gene with primers AGP1 and scFvP2. WT = wild type. B, RNA extracted from leaves of the plants in A was used in a reverse-transcriptase PCR assay to analyze expression of the $A G-s c F v$ fusion gene with the same set of primers in A. C, Proteins extracted from leaves in A were fractionated by electrophoresis on a $12 \%$ sodium dodecyl sulfate polyacrylamide gel and then subjected to immunoblot analysis with an antibody against the Histidine 6 tag.

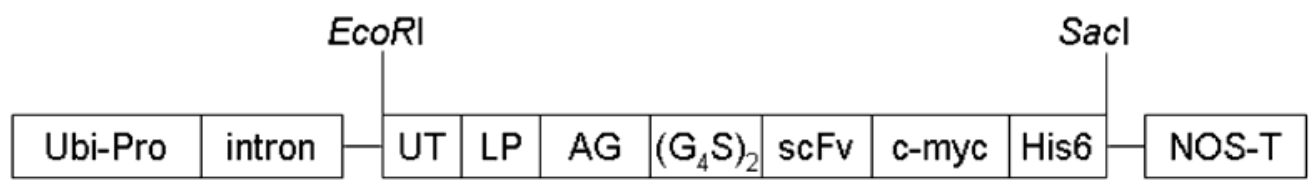

Fig. 1. Structure of AG-D2 fusion construct. An antifungal peptide sequence from Aspergillus giganteus (AG) and a single-chain Fv (scFv) antibody coding region from chicken were connected by a sequence encoding a 10-amino-acid glycine-serine linker. The $A G$-scFv fusion construct was inserted into the plant expression vector pAHC25 using EcoRI and SacI sites. Ubi-Pro, maize ubiquitin promoter; intron, the first intron from the ubiquitin promoter; UT, 5' untranslated region of the petunia chalcone synthase gene; LP, original mouse leader peptide sequence; c-myc, c-myc epitope tag; His6, histidine 6 tag; Nos-T, Nos terminator. 
lated by spraying Fusarium conidia. The disease severities were evaluated at 7, 14, and $21 \mathrm{dpi}$ and were expressed as the percentages of infected spikelets that were then converted into area under the disease progress curve (AUDPC). The AUDPC of all four transgenic wheat lines were significantly lower than the nontransgenic Bobwhite $(P<0.01)$ (Table 1$)$, with disease reductions ranging from 28 to $41 \%$. Furthermore, in comparison with FHB-resistant cv. Sumai3, transgenic line 12 showed a significant reduction of up to $26 \%(P<0.01)$ in AUDPC. Thus, the expression of the antibody fusion enhanced the resistance of wheat plants to initial infection by Fusarium pathogens. The disease symptoms on wheat spikes and grains were visually very distinctive between the transgenic wheat plants expressing the antibody fusion and the nontransgenic Bobwhite at 21 days after single floret injection and spraying inoculation (Fig. 4).

\section{Yield component analysis in $\mathrm{T} 3$ transgenic plants.}

To further evaluate the effects of the antibody fusion on the yields in the transgenic wheat plants, relative grain thousand

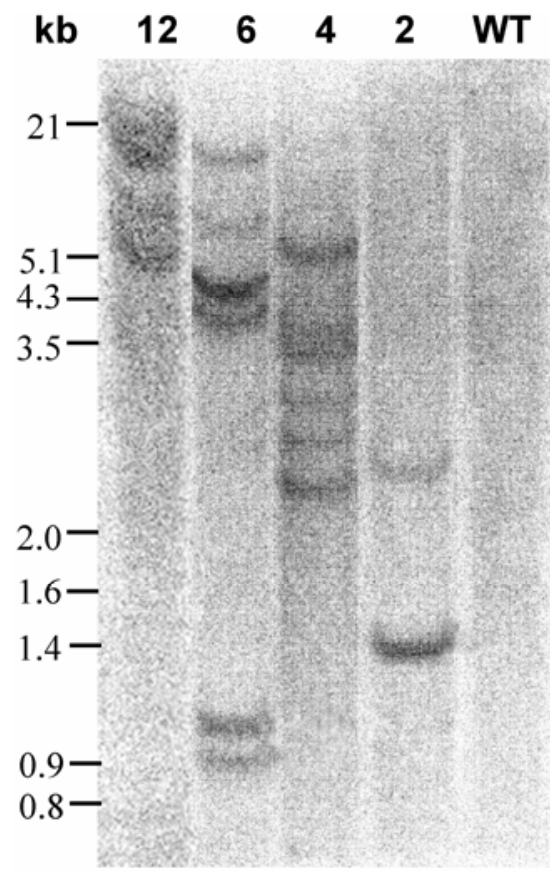

Fig. 3. Southern blot analysis of transgenic wheat. DNA extracted from leaves of T3 transgenic wheat lines 2, 4, 6, and 12 and the nontransgenic Bobwhite (Bob) were digested with $S a c$ I, resolved on a agarose gel, transferred to a Hybond ${ }^{+}$membrane, and probed with a single-chain Fv antibody gene probe. The positions of molecular weight markers in kilobases are indicated on the left; WT = wild type. weights (RGTW) of the T3 transgenic lines and the nontransgenic Bobwhite and Sumai3 were assessed immediately after harvest of wheat spikes inoculated by single-floret injection and spraying with Fusarium conidia. All four transgenic wheat lines remarkably increased their grain weights, ranging from 3.3- to 4.7-fold compared with the nontransgenic Bobwhite after single-floret inoculation (Fig. 5A). Such increases of RGTW in the transgenic lines were comparable with that from Sumai3. After spraying inoculation, increases of RGTW from 40 to $145 \%$ in the transgenic lines were obtained in comparison with the nontransgenic Bobwhite (Fig. 5B). Moreover,

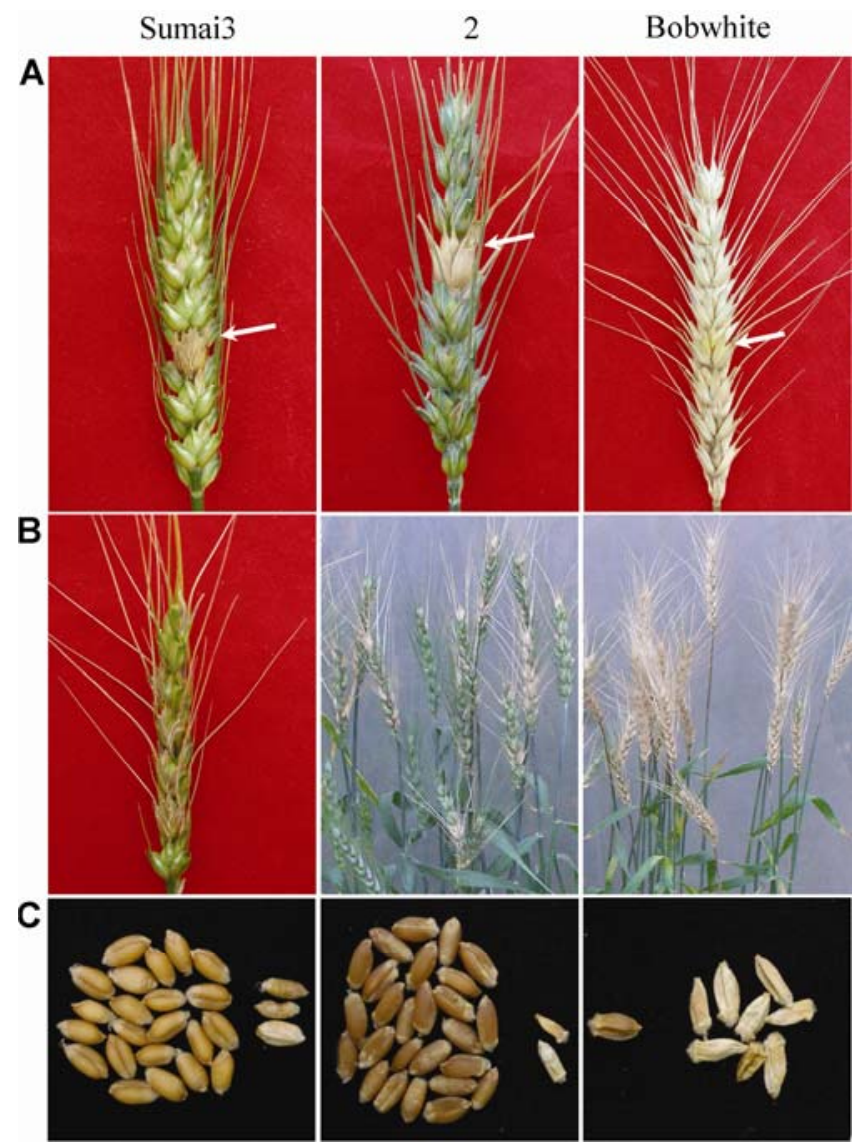

Fig. 4. Phenotype of representative spikes and grains from $\mathrm{T} 3$ transgenic wheat line 2, the nontransgenic Fusarium head blight (FHB)-susceptible cv. Bobwhite, and FHB-resistant cv. Sumai3 at 21 days postinoculation with the conidia of Fusarium asiaticum. A, Spikes of a single floret (indicated by an arrow) inoculated with the conidia of $F$. asiaticum. B, Spikes by spray inoculation with the conidia of $F$. asiaticum. C, Grains from a spike of a single-floret inoculation in A.

Table 1. Fusarium head blight resistance in $\mathrm{T} 2$ and $\mathrm{T} 3$ transgenic wheat

\begin{tabular}{|c|c|c|c|c|c|c|c|}
\hline \multirow[b]{3}{*}{ Genotype } & \multicolumn{6}{|c|}{ Single-floret injection, infected spikelet $(\%)$ at days postinoculation ${ }^{y}$} & \multirow{3}{*}{$\frac{\text { Spray, AUDPC }}{\text { z }}$} \\
\hline & \multicolumn{3}{|c|}{$\mathbf{T 2}$} & \multicolumn{3}{|c|}{ T3 } & \\
\hline & 7 & 14 & 21 & 7 & 14 & 21 & \\
\hline 2 & $6.67 \pm 0.00 b$ & $8.00 \pm 1.33 b$ & $13.33 \pm 3.65 b$ & $10.01 \pm 1.11 \mathrm{ab}$ & $14.49 \pm 1.95 \mathrm{~b}$ & $19.00 \pm 3.23 \mathrm{c}$ & $42.88 \pm 3.19 b c$ \\
\hline 4 & $7.14 \pm 0.48 b$ & $17.14 \pm 5.41 \mathrm{~b}$ & $20.00 \pm 8.56 b$ & $14.20 \pm 2.11 \mathrm{a}$ & $32.17 \pm 3.27 b$ & $34.48 \pm 3.22 \mathrm{~b}$ & $41.46 \pm 3.40 \mathrm{bc}$ \\
\hline 6 & $7.12 \pm 0.56 b$ & $14.44 \pm 4.36 b$ & $22.22 \pm 8.72 b$ & $4.89 \pm 1.59 b$ & $12.98 \pm 4.75 \mathrm{c}$ & $27.46 \pm 10.88 b c$ & $43.89 \pm 2.19 b$ \\
\hline 12 & $7.08 \pm 0.42 \mathrm{~b}$ & $9.22 \pm 4.36 \mathrm{~b}$ & $15.33 \pm 6.55 b$ & $16.81 \pm 2.44 \mathrm{a}$ & $26.51 \pm 3.49 c$ & $37.85 \pm 3.50 \mathrm{~b}$ & $36.05 \pm 3.20 \mathrm{c}$ \\
\hline Sumai3 & $8.00 \pm 0.54 b$ & $10.56 \pm 0.42 b$ & $13.78 \pm 1.36 b$ & $7.00 \pm 0.75 a b$ & $7.17 \pm 0.63 c$ & $7.20 \pm 0.31 \mathrm{~d}$ & $48.48 \pm 1.90 b$ \\
\hline Bobwhite & $19.58 \pm 3.48 \mathrm{a}$ & $34.17 \pm 3.44 \mathrm{a}$ & $92.50 \pm 7.50 \mathrm{a}$ & $18.79 \pm 8.33 \mathrm{a}$ & $58.21 \pm 10.24 \mathrm{a}$ & $90.91 \pm 9.09 \mathrm{a}$ & $60.55 \pm 1.17 \mathrm{a}$ \\
\hline
\end{tabular}

${ }^{\mathrm{y}}$ Infected spikelets $(\%)$ are an average \pm standard error from 30 spikes from 30 wheat plants per line. Different letters at the same timepoint indicate statistical significance $(P<0.01)$ with Student's $t$ test.

${ }^{\mathrm{z}}$ For spray inoculation, percentages of infected spikelets were evaluated 7,14 , and 21 days postinoculation and converted to area under the disease progress curve (AUDPC) with standard error from 30 spikes from 30 wheat plants per line. Different letters indicate statistical significance $(P<0.01)$ with Student's $t$ test. 
RGTW of transgenic line 2 after single-floret inoculation was significantly higher (up to 20\%) than that of FHB-resistant cv. Sumai3 $(P<0.01)$.

\section{DISCUSSION}

The transgenic wheat plants expressing a Fusarium spp.specific antibody fused to an antifungal peptide displayed a significantly enhanced resistance when challenged with a highly aggressive FHB pathogen. This resistance is inheritable in different generations and may represent the first demonstration for antibody-based protection of a crop against a devastating fungal pathogen.

Both single-floret injection and spraying inoculations were deployed to evaluate resistance responses of the transgenic wheat plants in a plastic house. In single-floret injection, all the inoculated spikelets were injected with equal amounts of $\mathrm{Fusa}$ rium macroconidia and had the same events of initial infection. The fungal growth and development on the wheat spikes were assayed based on the fungal spreading rates postinoculation and expressed as the percentage of infected spikelets, namely type II resistance (Table 1), that represents the major FHB resistance observed in natural germplasms such as Sumai3 (Bai and Shaner 2004) and engineered wheat plants (Anand et al. 2003; Chen et al. 1999; Makandar et al. 2006). On the other hand, in spraying inoculation, the macroconidial spores were sprayed on the surface of spikes and the subsequent initial infection could vary depending on the composition and nature of the wheat spike tissues whereby the macroconidia stand. The differences of the disease symptoms on the inoculated wheat spikes comprise the variations of initial infection and the succeeding development of fungus and, consequently, are expressed as AUDPC (Table 1). Thus, the reduction of the fungal infection revealed in the spraying inoculation is termed as type I resistance (Buerstmayr et al. 2000; Steed et al. 2005). The present results showed that all four transgenic wheat lines displayed a significantly enhanced FHB resistance at 21 days after single floret injection and spraying inoculation compared with the nontransgenic Bobwhite (Table 1), indicating that the antibody fusion conferred not only type II but also type I resistance. Furthermore, three transgenic wheat lines displayed a higher level of type I resistance than Sumai3 (Table 1), the best natural FHB-resistant cultivar available whose genetic basis for types I ( $\mathrm{Li}$ et al. 2000) and II (Li et al. 2000; Liu and Anderson 2003; Waldron et al. 1999) FHB resistance has been identified. The two types of resistance combined will generate more durable and widely applicable resistance and the antibody fusion gene could be used as a novel candidate for improving FHB resistance in plants.

The current findings are consistent with a previous report that the expression of the $A G-s c F v$ fusion conferred a very significant enhancement to infection of $F$. oxysporum in Arabidopsis plants (Peschen et al. 2004). The antibody fusion comprises a Fusarium spp.-specific single-chain antibody derived from chicken and an antifungal peptide from A. giganteus (Wnendt et al. 1990). The antibody was isolated by phage display with the mycelium cell wall proteins from strain 5035 of $F$. asiaticum. The antibody fusion used in this study showed a high specificity and affinity toward Fusarium spp. in vitro and strongly inhibited the fungal growth by damaging the mycelium cell walls as revealed by in vitro assays (Peschen et al. 2004). Expression in wheat of the antibody fusion provided a significantly enhanced resistance to both the initial infection and the fungal spreading of the FHB pathogen (Table 1; Fig. 4). It is likely that the Fusarium spp.-specific antibody within the fusion protein played a vital role in delivering the fusion into the fungal infection structures in plant tissues, whereby the antibody directly interacted with the fungal antigens and the antifungal peptide damaged the mycelium membranes to interfere the fungal development (Bohlmann 2004; Lacadena et al. 1995; Peschen et al. 2004). Constitutive expression in planta regulated by the maize ubiquitin promoter would provide a continual supply of the antibody fusion proteins that were secreted into apoplast (achieved using a plant or animal leader peptide sequence contained in the expression construct) (Voss et al. 1995) or accumulated surrounding the fungal infection structures in plant tissues, resulting in an effective restriction of fungal infection and growth.

Analyses of yield components revealed that plants expressing the antibody fusion produced up to 4.7 -fold and $145 \%$ more grain than the nontransgenic Bobwhite after inoculation with single-floret injection and spraying inoculation, respectively, in the T3 generation (Fig. 5). This is highly consistent with the enhanced level of FHB resistance conferred by the antibody fusion protein. At $21 \mathrm{dpi}$ after single-floret injection, the nontransgenic Bobwhite had a 4.8-fold increase $(90.91 \%)$ of infected spikelets compared with the most resistant trans-
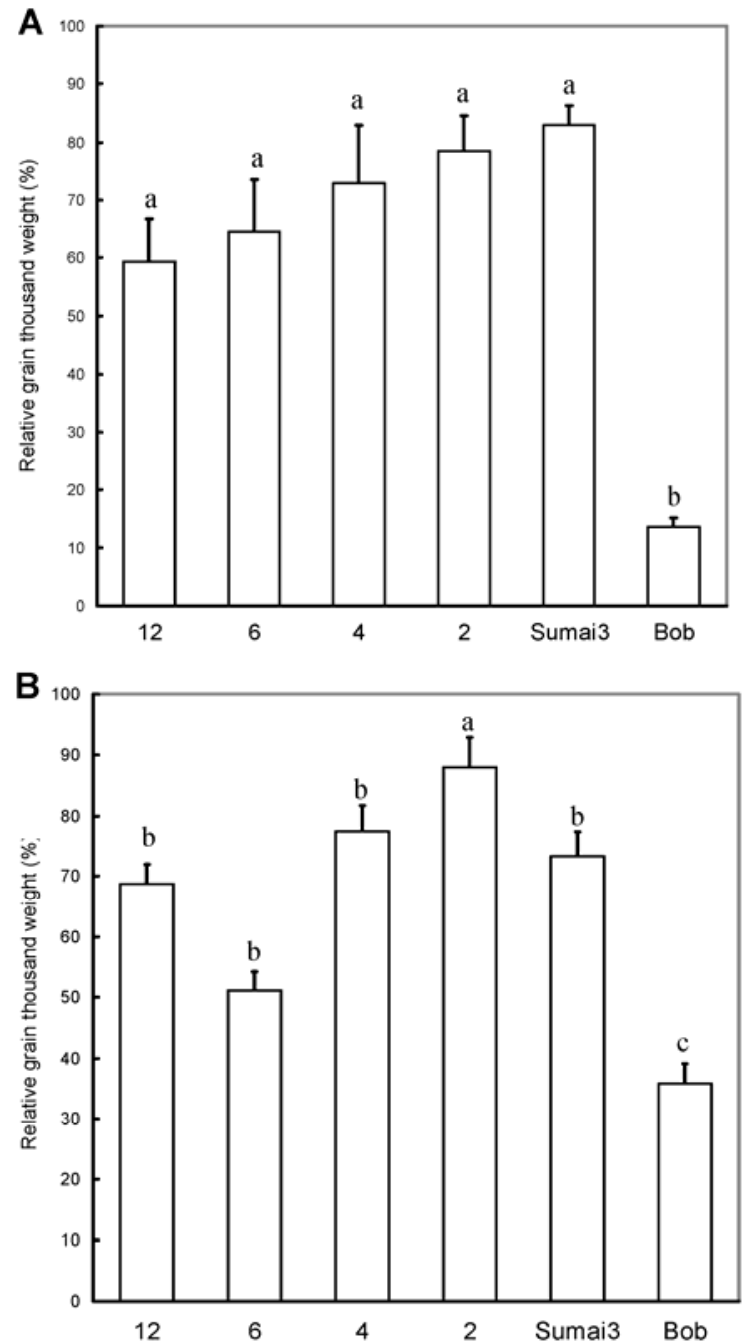

Fig. 5. Comparison of yield parameters between nontransgenic plants and transgenic plants expressing the antibody fusion. Grain weights were measured for the four transgenic wheat lines of T3 generation and the nontransgenic Bobwhite and Sumai3 with and without inoculation with Fusarium asiaticum. Relative grain thousand weights were calculated based on the ratio of the grain weights between the inoculated spikes and noninoculated spikes for each plant line or cultivar and expressed as an average \pm standard error from 30 spikes of 30 wheat plants. A, Singlefloret inoculation and B, spray inoculation. Different letters indicate statistical significance $(P<0.01)$ with Student's $t$ test. 
genic line 2 (19\%) under the same conditions (Table 1). Also at 21 days after spraying inoculation, the AUDPC of the nontransgenic Bobwhite was 1.68 -fold $(60.55 \%)$ compared with the most resistant transgenic line $12(36.05 \%)$ (Table 1). Line 6 displayed the highest AUDPC among the four transgenic lines (Table 1), in accordance with the lowest RGTW (Fig. 5). Nevertheless, a lower RGTW in line 6 than in Sumai3 that had a higher AUDPC may reflect structural or physiological discrepancies of spikes and kernels between two genotypes in response to spray inoculation by an FHB pathogen. Therefore, 21 dpi appears to be the appropriate end point for the assessment of FHB resistance in transgenic wheat plants that properly reflects the yield potentials of the assayed plants.

Fusarium sp. strain 5035, used throughout this study, was isolated from a scabby wheat spike from Wuhan, China and belonged to $F$. asiaticum, the predominant species on wheat spikes in China (Qu et al. 2008) according to the classification of phylogenetic species recently defined by O'Donnell and associates (2004). This strain is a highly aggressive pathogen during the infection of florets and seedlings in wheat (Wu et al. 2005) and produces deoxynivalenol (DON) and 15-Ac-DON mycotoxins (Zhang et al. 2007). Plastic houses used for the resistance assays were aimed at the prevention of cross inoculation of Fusarium pathogens and keeping humidity during the infection period. Conditions inside the plastic houses were similar to the natural field environment in Wuhan, located in the middle region of the Yangtze River valley. The FHB resistance assays carried out in the plastic houses would be comparable with that obtained in field. The difference of FHB resistance between $\mathrm{T} 2$ and $\mathrm{T} 3$ generations (Table 1) may be due to environmental variations between two years. The current study demonstrated a significant enhancement of FHB resistance by the expression of Fusarium spp.-specific antibody fusion in transgenic wheat plants, which would be used as a foundation for breeding commercial wheat cultivars with enhanced FHB resistance via genetic engineering. The antibody-based approach would be deployed as an effective strategy for reduction of mycotoxins in fields while public acceptance for transgenic solutions is widely established.

\section{MATERIALS AND METHODS}

\section{Plasmids.}

The coding sequence of an antifungal peptide gene from $A$. giganteus (AG) (Wnendt et al. 1990) was joined to the $5^{\prime}$ end of the coding sequence of a $s c F v$ gene (accession no. AJ517190) derived from chicken to construct the $A G-s c F v$ fusion (Peschen et al. 2004). The fusion gene construct was released by EcoRI and SacI and inserted into the same restriction enzyme sites of the plasmid pAHC25 (Christensen and Quail 1996). The recombinant plasmid pAHC25 consists of the fusion construct and bar genes, each under the control of the maize ubiquitin promoter-intron (Fig. 1). In front of the $A G-s c F v$ fusion sequence, $5^{\prime}$ untranslated region from the petunia chalcone synthase gene and an original mouse leader peptide sequence were included (Voss et al. 1995). The bar gene encodes the enzyme phosphinothricin-acetyltransferase, which inactivates PPT, the active ingredient of the herbicides bialaphos and Basta.

\section{Plant materials and culture.}

Wheat plants (Triticum aestivum L. cv. Bobwhite) were grown in the field in Wuhan, China and spikes were collected approximately 14 days postanthesis. Immature caryopses were sterilized with $70 \%$ ethanol for $5 \mathrm{~min}$ and $0.1 \%$ (vol/vol) Mercuric chloride for $10 \mathrm{~min}$ and rinsed three times with sterile, distilled water. Immature embryos were excised, bombarded, and selected as described (Altpeter et al. 1996). Surviving plants with well-developed roots were grown in a growth chamber $\left(25^{\circ} \mathrm{C}, 16 \mathrm{~h}\right.$ of light and $8 \mathrm{~h}$ of darkness). Regenerated plants were evaluated for herbicide resistance by painting or spraying with a $0.2 \%$ (vol/vol) solution of Liberty (containing $18.19 \%$ DL-phosphinothricin).

\section{Microprojectile bombardment.}

A biolistic gun, PDS-1000 He (Bio-Rad, Hercules, CA U.S.A.), was used in this experiment. Prior to bombardment, $1-\mu \mathrm{m}$ gold particles were coated with the recombinant pAHC25 DNA by using the method of Nehra and associates (1994). The immature embryos were placed in the center of a 90-by-15-mm petri dish. All bombardments were performed at a pressure of 1,100 psi. Each plate was bombarded once at particle travel distances of $9 \mathrm{~cm}$. The distance between the rupture disk and the macrocarrier and that of macrocarrier travel were 12 and $8 \mathrm{~mm}$, respectively.

\section{PCR and Southern blot analysis.}

Total DNA was isolated from leaves of wheat plants according to a cetyltrimethylammonium bromide method (Nicholson and Parry 1996). Two sets of gene-specific primers were used for PCR identification of transgenes in transgenic plants: i) AGP1 (5'-ATCAGCGCCTCAGTTATCATC-3') and AGP2 (5'ACGCGTCGACGCAGTAGCACT-3') and ii) scFvP1 (5'TGTGGAACCGGAGAATCGTGA-3') and scFvP2 (5'-TGAG GACACCGCCACCTACTA-3'). Amplifications were carried out with thermal cycling consisting of 30 cycles of denaturation $\left(94^{\circ} \mathrm{C}, 1.5 \mathrm{~min}\right)$, annealing $\left(55^{\circ} \mathrm{C}, 1 \mathrm{~min}\right)$, and extension $\left(72^{\circ} \mathrm{C}, 2 \mathrm{~min}\right)$. PCR products were separated on $1 \%$ agarose gels. For Southern blotting, the DNA ( $15 \mu \mathrm{g}$ per sample) was digested with 60 units of restriction enzyme SacI overnight and electrophoresed on $0.8 \%$ agarose gels. DNA fragments were transferred onto a nylon membrane (Hybond-N ${ }^{+}$; Amersham, Bucks, U.K.) and hybridized with a- $\left[{ }^{32} \mathrm{P}\right]-\mathrm{dCTP}-$ labeled DNA fragments derived from the coding sequence of a singlechain antibody gene (Peschen et al. 2004) according to standard protocols (Sambrook et al. 1989). Autoradiograph was performed with Imaging Plate and Cassette (Fuji Film, Tokyo) and analyzed with a Fuji BAS1800-II system (BAS1800-II; Fuji Film).

\section{RT-PCR and Western blot analysis.}

Wheat leaves were ground to fine powders in liquid nitrogen and total leaf RNA was isolated using TRIZOL reagent and treated with RNase-free DNase I (Takara, Dalian, China). The plant RNA was subjected to reverse transcription with Superscript III and an oligo-d $\mathrm{T}_{20}$ random primer according to the instruction of the supplier (Invitrogen, Carlsbad, CA, U.S.A.). The synthesized cDNAs were used as template for RT-PCR with the antibody fusion gene specific primers AGP1 and scFvP2 under the condition of PCR amplifications described above.

Total proteins were extracted from the ground leaf powders with the protein extraction buffer $(50 \mathrm{M}$ Tris- $\mathrm{HCl}, \mathrm{pH} 7.8 ; 1$ mM EDTA; and $1 \mathrm{mM}$ phenylmethansulfonyl fluoride). After centrifugation of the extracts $\left(12,000 \times \mathrm{g}, 4^{\circ} \mathrm{C}, 20 \mathrm{~min}\right)$, the supernatant was stored at $4^{\circ} \mathrm{C}$ with the addition of $0.01 \%$ (wt/vol) sodium azide for preservation. Protein concentrations were determined with the Bradford assay (Bradford 1976) using bovine serum albumin as the protein standard. Wheat leaf protein extracts were separated on $12 \%$ sodium dodecyl sulfate polyacrylamide gels and transferred to nitrocellulose membrane. Fusion proteins were detected with anti-His tag antibody as the primary antibody and with the secondary antibody of goat antimouse antibody conjugated to alkaline phosphotase (Peschen et al. 2004). 


\section{FHB resistance assay.}

For single-floret inoculation, the macroconidia suspension of $F$. asiaticum isolate 5035 (Qu et al. 2008) was adjusted to a concentration of $5 \times 10^{5}$ spores $/ \mathrm{ml}$. At midflowering time, 30 spikes of each line, 1 spike per plant, were inoculated with a $10-\mu l$ droplet of the conidia, which was injected by a pipette tip to the central floret of one middle spikelet (Wu et al. 2005). The fungus-inoculated plants were kept humid in the plastic house for 3 days. The fungal spreading rates on the inoculated spikes (type II reaction) were evaluated 7, 14, and 21 dpi. For each spike, the percentage of the infected spikelets spreading from the inoculated spikelets was determined.

For spraying inoculation, the macroconidia suspension was adjusted to a concentration of $5 \times 10^{4} / \mathrm{ml}$ with $0.1 \%$ (vol $/ \mathrm{vol}$ ) Tween 20 solution. At the same stage as for the single-floret inoculation, the wheat spikes were sprayed once by a portable sprayer until the whole spikes were fully covered by the conidia suspension in the plastic house. The sprayed plants were kept humid for 3 days. Visual disease symptoms were recorded 7,14 , and $21 \mathrm{dpi}$ and the percentage of the infected spikelets (type I reaction) was scored according to a linear 0-to-4 $(0=$ no disease to $4=100 \%$ infected spikelets) scale. Scoring between 0 and 1 was further made in 0.1 scale increments and between 1 and 4 in 0.5 intervals. The AUDPC was calculated for each line according to equations described by Buerstmayr and associates (2000).

\section{Estimation of yield components.}

After maturation, wheat spikes were harvested from which grains were taken by hand and measured after drying. Mean grain thousand weights were determined for the T3 transgenic plants, Bobwhite, and Sumai3 inoculated by single-floret injection and spraying inoculation as well as for the noninoculated controls. The data were expressed as the percentages of noninoculated controls for each line or cultivar and are referred to as the RGTW, as described by Steed and associates (2005).

\section{Statistical analysis.}

Student's $t$ tests and least significant difference analysis were used to compare FHB resistances and yield components among each transgenic line, the nontransgenic FHB-susceptible cv. Bobwhite, and FHB-resistant cv. Sumai3 with SAS software (version 8.1; SAS Institute, Cary, NC, U.S.A.).

\section{ACKNOWLEDGMENTS}

This work was supported by the National Natural Science Foundation of China (30530510, 30571160, and 30711120181), the Ministry of Science and Technology of China (2006BAK02A12 and 2007AA10Z425) and the Ministry of Agriculture of China (948).

\section{LITERATURE CITED}

Anand, A., Zhou, T., Trick, H. N., Gill, B. S., and Muthukrishnan, S. 2003. Greenhouse and field testing of transgenic wheat plants stably expressing genes for thaumatin-like protein, chitinase and glucanase against Fusarium graminearum. J. Exp. Bot. 54:1001-1111.

Altpeter, F., Vasil, V., Saivastava, V., Stöger, E., and Vasil, I. K. 1996. Accelerated production of transgenic wheat (Triticum aestivum L.) plants. Plant Cell Rep. 16:12-17.

Bai, G.-H., and Shaner, G. 2004. Management and resistance in wheat and barley to Fusarium head blight. Annu. Rev. Phytopathol. 4:135-161.

Bai, Q. Y., 1997. The contamination of fungal mycotoxins in products. J. Agro-Environ. Sci. 16:40-43.

Bohlmann, H. 2004. The best of both worlds in plant protection. Nat. Biotechnol. 22:682-683.

Boonrod, K., Galetzka, D., Nagy, P. D., Conrad, U., and Krczal, G. 2004. Single-chain antibodies against a plant viral RNA-dependent RNA polymerase confer virus resistance. Nat. Biotechnol. 22:856-862.
Bradford, M. M. 1976. A rapid and sensitive method for quantitation of microgram quantities of protein utilizing the principle of protein-dyebinding. Anal. Biochem.72:248-254.

Buerstmayr, H., Steiner, B., Lemmens, M., and Ruckenbauer, P. 2000. Resistance to Fusarium head blight in winter wheat: Heritability and trait associations. Crop Sci. 40:1012-1018.

Chen, L. F., Bai, G. H., and Desjardins, A. E. 2000. Recent advances in wheat head scab research in China. National Agricultural Library Internet Publication, U. S. Department of Agriculture, Beltsville, MD, U.S.A. Published online

Chen, W. P., Chen, P. D., Liu, D. J., Kynast, R., Friebe, B., Velazhahan, R., Muthukrishnan, S., and Gill, B. S. 1999. Development of wheat scab symptoms is delayed in transgenic wheat plants that constitutively express a rice thaumatin-like protein gene. Theor. Appl. Genet. 99:755-760.

Christensen, A. H., and Quail, P. H. 1996. Ubiquitin promoter-based vectors for high level expression of selectable and/or screenable marker genes in monocotyledonous plants. Transgenic Res. 5:213-218.

Dahleen, L. S., Okubara, P. A., and Blech, A. E. 2001. Transgenic approaches to combat Fusarium head blight in wheat and barley. Crop Sci. 41:628-637.

Di, R., and Tumer, N. E. 2005. Expression of a truncated form of ribosomal protein L3 confers resistance to pokeweed antiviral protein and the Fusarium mycotoxin deoxynivalenol. Mol. Plant-Microbe Interact. 18:762-770.

Gale, L. R., Chen, L. F., Hernick, C. A., Takamura, K., and Kistler, H. C. 2002. Population analysis of Fusarium graminearum from wheat fields in eastern China. Phytopathology 92:1315-1322.

Hiatt, E. E., Hill, N. S., and Hiatt, E. N. 2001. Monoclonal antibodies incorporated into Neotyphodium coenophialum fungal cultures: Inhibition of fungal growth and stability of antibodies. Fungal Genet. Biol. 33:107-114.

Jobling, S. A., Jarman, C., Teh, M.-M., Holmberg, N., Blake, C., and Verhoeyen, M. E. 2003. Immunomodulation of enzyme function in plants by single-domain antibody fragments. Nat. Biotechnol. 21:77-80.

Lacadena, J., Martinez del Pozo, A., Gasset, M., Patino, B., CamposOlivas, R., Vazquez, C., Martinez-Ruiz, A., Mancheno, J. M., Onaderra, M., and Gavilanes, J. G. 1995. Characterization of the antifungal protein secreted by the mould Aspergillus giganteus. Arch. Biochem. Biophys. 324:273-281.

Li, B., Liu, F., Xu, R., Huang, C., Cheng, F., Liu, J., Meng, J., and Mou, J. 2000. Sumai3: Its development, genetic characteristics and applications in wheat breeding for Fusarium head blight resistance. Pages 187-193 in: Proc. Int. Symp. Wheat Improvement for Scab Resistance. Suzhou and Nanjing, China.

Liu, D. J. 2002. Genome analysis in wheat breeding for disease resistance. Acta Bot. Sin. 44:1096-1114.

Liu, S., and Anderson, J. A. 2003. Marker assisted evaluation of Fusarium head blight resistant wheat germplasm. Crop Sci. 43:760-766.

Mackintosh, C., Lewis, J., Radmer, L., Shin, S., Heinen, S., Smith, L., Wyckoff M, Dill-Macky, R., Evans, C., Kravchenko, S., Baldridge, G., Zeyen, R., and Muehlbauer, G. 2007. Overexpression of defense response genes in transgenic wheat enhances resistance to Fusarium head blight. Plant Cell Rep. 26:479-488.

Makandar, R., Essig, J. S., Schapaugh, M. A., Trick, H. N., and Shah, J. 2006. Genetically engineered resistance to Fusarium head blight in wheat by expression of Arabidopsis NPR1. Mol. Plant-Microbe Interact. 19:123-129.

Nehra, N. S., Chibbar, R. N., Leung, N., Caswell, K., Mallard, C., Steinhauer, L., Baga, M., and Kartha, K. K. 1994. Self-fertile transgenic wheat plants regenerated from isolated scutellar tissues following microprojectile bombardment with two distinct gene constructs. Plant J. 5:285-297.

Nicholson, P., and Parry, D. W.1996. Development and use of a PCR assay to detect Rhizoctonia cerealis, the cause of sharp eyespot in wheat. Plant Pathol. 45:872-883.

O'Donnell, K., Ward, T. J., Geiser, D. M., Kistler, H. C., and Aoki, T. 2004. Genealogical concordance between the mating type locus and seven other nuclear genes supports formal recognition of nine phylogenetically distinct species within the Fusarium graminearum clade. Fungal Genet. Biol. 41:600-623.

Okubara, P. A., Blech, A. E., McCormick, S. P., Alexander, N. J., DillMacky, R., and Hohn, T. M. 2002. Engineering deoxynivalenol metabolism in wheat through the expression of a fungal trichothecene acetyltransferase gene. Theor. Appl. Genet. 106:74-83.

Peschen, D., Li, H. P., Fischer, R., Kreuzaler, F., and Liao, Y. C. 2004. Fusion proteins comprising a Fusarium-specific antibody linked to antifungal peptides protect plants against fungal pathogens. Nat. Biotechnol. 22:732-738.

Qu, B., Li, H. P., Zhang, J. B., Xu, Y. B., Huang, T., Wu, A. B., Carter, J., Nicholson, P., and Liao, Y. C. 2008. Geographical distribution and ge- 
netic diversity of the Fusarium graminearum and $F$. asiaticum on wheat spikes throughout China. Plant Pathol. 57:15-24.

Sambrook, J., Fritsch, E. F., and Maniatis, T. 1996. Molecular Cloning: A Laboratory Manual, 3rd ed. Cold Spring Harbor Laboratory Press, Cold Spring Harbor, NY, U.S.A.

Steed, A., Chandler, E., Thomsett, M., Gosman, N., Faure, S., and Nicholson, P. 2005. Identification of type I resistance to Fusarium head blight controlled by a major gene located on chromosome 4A of Triticum macha. Theor. Appl. Genet. 111:521-529.

Tavladoraki, P., Benvenuto, E., Trinca, S., Demartinis, D., Cattaneo, A., and Galeffi, P. 1993. Transgenic plants expressing a functional singlechain Fv-antibody are specifically protected from virus attack. Nature 366:469-472.

Voss, A., Niersback, M., Hain, R., Hirsch, H. J., Liao, Y. C., Kreuzaler, F., and Fischer, R. 1995. Reduced virus infectivity in N. tabacum secreting a TMV-specific full size antibody. Mol. Breed. 1:39-50.

Waldron, B. L., Moreno-Sevilla, B., Anderson, J. A., Stack, R. W., and Frohberg, R. C. 1999. RFLP mapping of QTL for Fusarium head blight resistance in wheat. Crop Sci. 39:805-811.
Windels, C. E., 2000. Economic and social impacts of Fusarium head blight: Changing farms and rural communities in the Northern Great Plains. Phytopathology 90:17-21.

Wnendt, S., Ulbrich, N., and Stahl, U. 1990. Cloning and nucleotide sequence of a cDNA encoding the antifungal protein of Aspergillus giganteus and preliminary characterization of the native gene. Nucleic Acid Res. 18:3987.

Wu, A. B., Li, H. P., Zhao, C. S., and Liao, Y. C. 2005. Comparative pathogenicity of Fusarium graminearum from China revealed by wheat coleoptile and floret inoculations. Mycopathologia 160:75-83.

Zhang, J. B., Li, H. P., Dang, F. J., Qu, B., Xu, Y. B., Zhao, C. S., and Liao, Y. C. 2007. Determination of the trichothecene mycotoxin chemotypes and associated geographical distribution and phylogenetic species of the Fusarium graminearum clade from China. Mycol. Res. 111:967975.

Zimmermann, S., Schillberg, S., Liao, Y. C., and Fischer, R. 1998. Intracellular expression of TMV-specific single-chain Fv fragments leads to improved virus resistance in Nicotiana tabacum. Mol. Breed. 4:369379. 